\title{
A Simulation Analysis of an Influenza Vaccine Production Plant in Areas of High Humanitarian Flow. A Case Study for the Region of Norte de Santander (Colombia).
}

\author{
Jefferson Eduardo Contreras-Ropero ${ }^{1}$, Silvia Liliana Ruiz-Roa ${ }^{2}$, Janet B. García-Martínez ${ }^{1}$, Néstor A. Urbina-Sua- \\ rez ${ }^{1}$, Germán L. López-Barrera ${ }^{1}$, Andrés F. Barajas-Solano ${ }^{1}$, and Antonio Zuorro ${ }^{3, *}$
1 Department of Environmental Sciences, Universidad Francisco de Paula Santander, Av. Gran Colombia No. 12E-96, Cucuta 540003, Colombia; jeffersoneduardocr@ufps.edu.co (J.E.C-R.); janetbibi- anagm@ufps.edu.co (J.B.G.-M.); nestorandresus@ufps.edu.co (N.A.U-S); lucianolb@ufps.edu.co (G.L.L-B); andresfernandobs@ufps.edu.co (A.F.B-S.).
2 Department of Clinical care and rehabilitation, Universidad Francisco de Paula Santander, Av. Gran Colom- bia No. 12E-96, Cucuta 540003, Colombia; silvialilianarr@ufps.edu.co (S.L.R-R.).
3 Department of Chemical Engineering, Materials and Environment, Sapienza University, Via Eudossiana 18, 00184 Roma, Italy
* Correspondence: antonio.zuorro@uniroma1.it

\begin{abstract}
The production of vaccines of biological origin presents a tremendous challenge for researchers. In this context, animal cell cultures are an excellent alternative for the isolation and production of biologicals against several viruses since they have an affinity with viruses and a great capacity for their replicability. Different variables have been studied to know the system's ideal parameters, allowing it to obtain profitable and competitive products. Consequently, this work focuses its efforts on evaluating an alternative for producing an anti-influenza biological from MDCK cells using SuperPro Designer v8.0 software. The process uses the DMEN culture medium supplemented with nutrients as raw material for cell development; the MDCK cells were obtained from a potential scale-up with a final working volume of $500 \mathrm{~L}$, four days of residence time, inoculum volume of $10 \%$, and continuous working mode with up to a total of $7400 \mathrm{~h} / \mathrm{Yr}$ of work. The scheme has the necessary equipment for the vaccine's production, infection, and manufacture with yields of up to 416,698 units/h. In addition, it was estimated to be economically viable to produce recombinant vaccines with competitive prices of up to $0.31 \mathrm{USD} /$ unit.
\end{abstract}

Keywords: Modeling process; SuperPro Designer ${ }^{\circledR}$, Cell Culture; Public health; Developing countries

\section{Introduction}

Influenza is an acute viral infection that can cause symptoms ranging from mild to severe, including bronchitis, pneumonia, and death, especially in patients with risk factors [1]. Unlike in the United States, where there is one influenza season, in Colombia it occurs throughout the year. According to the Colombian National Institute of Health (NIH-Colombia), during the year there are two peaks that vary according to the city. The first peak occurs between the months of March to June and then decreases during the months of July to August; and the second peak occurs between the months of September to November. In 2019, prior to COVID-19 emergency, approximately 6.7 million people suffered symptomatic influenza infection, with 21.712 hospitalizations in intensive care units, with high number of cases in the region of Norte de Santander [2]. This region is in the northeast of the country and shares a border with Venezuela. Due to the economic instability experienced by the neighboring country, the migration of people from Venezuela to other 
parts of Latin America has as a central point the flow of people through the border crossings of the cities of Cucuta and Villa del Rosario.

The Colombian Ministry of Health (MinSalud) formulated the Ten-Year Public Health Plan (PDSP) 2012-2021 in response to Law 1438 of 2011, being a concrete expression of a route to be followed for ten years by citizens, experts, and the national government in terms of public health, whose central axis is human development through equitable and equal access to health as a human right $[3,4]$. Norte de Santander is a region in Colombia that presents multiple and differentiated affectations to public health when comparing the PDSP indicators with those obtained at the national level, characterized by higher mortality rates due to communicable diseases and aggressions, becoming the two priority problems for action in the state.

In quantitative terms, the age-adjusted mortality rate for communicable diseases in Colombia for 2016 was 34.50, compared to Norte de Santander, which presented a rate of 46.08 for the same year, evidencing a persistence of the longitudinal elevation of said indicator compared to the national territory since 2013. In the infant and childhood population, respiratory diseases have been identified as one of the leading causes of mortality. Although mortality rates for acute respiratory infections in children under five years of age have decreased by more than $60 \%$ since 2005 , the state maintains that vaccination coverage is ineffective due to the low accessibility to biologicals that prevent this group of infections in this population, such as influenza. The best way to control influenza outbreaks is through vaccination [5]; however, barriers to global implementation of vaccine production such as limited manufacturing, vaccine cost and suboptimal efficacy [6] hampers the efforts to avoid unnecessary death. Due to the importance of vaccine production, to the best of the author's knowledge there are no companies in Colombia focused on the production of influenza vaccines.

SuperPro Designer ${ }^{\circledR}$ is a process simulator developed specifically for the modeling, evaluation, and optimization of bioprocess unit operations [7], which can be used from conceptual design, process operation and optimization [8], as well as process economics, and waste stream characterization [9]. In the present work, an economic study of an influenza vaccine production plant design model from MDCK cells was carried out using SuperPro Designer ${ }^{\circledR}$ v8.0 as an initial alternative for vaccine production in Colombia.

\section{Materials and Methods}

\subsection{Process description}

The process of vaccine production using recombinant viruses and animal cell cultures consists of three critical steps that correspond to two industrial faces of the process (Upstream and Downstream). The first step, known as Cell Propagation. MDCK (certified canine kidney) cells are produced in DMEM culture medium, which is composed of a higher number of amino acids, sodium pyruvate, vitamin B12, biotin, and ascorbic acid, which can be used with a wide variety of suspension cells and adherent mammalian cells, including keratinocytes, primary rat astrocytes, and human melanoma cells [10].

Once the desired cell concentration is obtained, the cells are transferred to fermenters with higher working volumes (pre-inoculum). When the fermenters reach the optimal cell density for virus propagation, the virus is transferred and incubated with the virus, giving way to the second stage known as virus infection and propagation $\left(30 \pm 2{ }^{\circ} \mathrm{C}, 250 \mathrm{rpm}\right.$ and $\mathrm{pH}$ of 6.0) [11]; the final stage consists of the liberation, elicitation, purification, inactivation and finally formulation and packaging (Figure 1). 


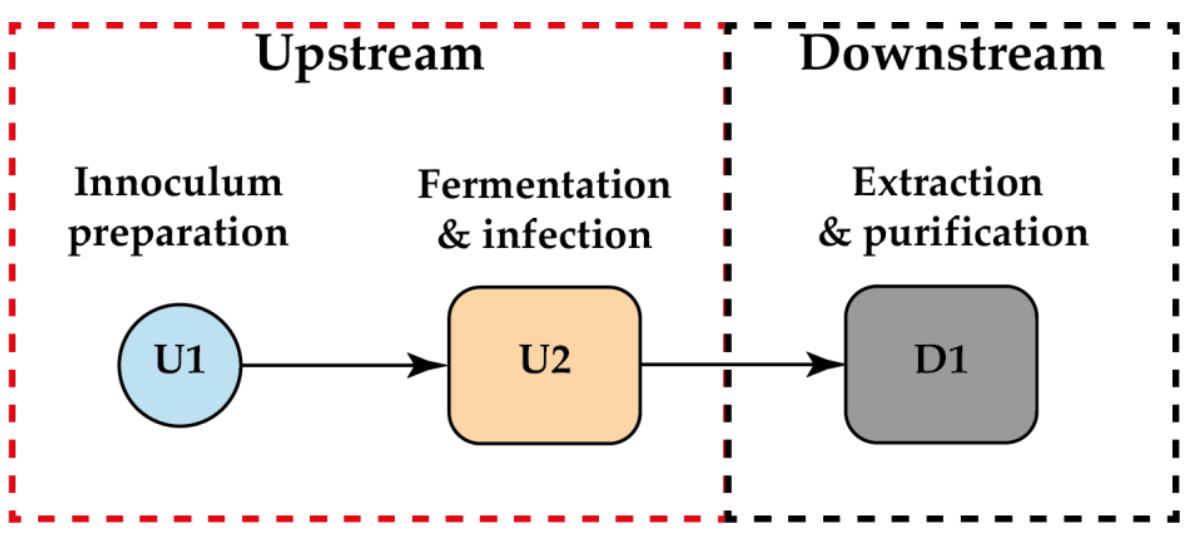

Figure 1. Process description of influenza vaccine production.

\subsection{Plant simulation}

The influenza vaccine production plant was simulated using SuperPro Designer ${ }^{\circledR}$ software v8.0. (Intelligen, Inc., Scotch Plains, NJ, USA). This software allows us to compare different pretreatment processes, production, consumption, and yields, making the process technically and economically feasible over time.

\section{Results}

The use of recombinant retroviruses and the massive culture of animal cell lines are fundamental techniques for the large-scale manufacture of biotechnological inputs to produce viral vaccines. These vaccines are recombinant molecules obtained by expressing or replacing exogenous gene fragments in the host cell genome, which can be dispensed in the other cell sequences [12]. However, the production of these retroviruses presents some difficulties, such as the need for a deep knowledge of the culture at different scales and the recovery technologies of these products; therein lies the importance of using simulation software to have production and cost estimates at the industrial level.

The use of simulators to model industrial processes is becoming more and more popular every day because it provides the opportunity to improve and reduce the time needed to generate different processes that integrate great applicability in different industrial branches [13]. These techniques are mainly based on the use and schematization of the process using mathematical tools and software, where all those independent and dependent variables (mass and energy balance) of the various biological and mechanical systems that make up the process are detailed to predict the natural behavior of the plant [14]. It also considers different aspects, including economic aspects such as construction, labor, equipment, waste, and total costs for the manufacturing and maintenance of the system. The operational, economic parameters of the system were classified in different sections: in the first one, we will find the total direct process costs (TIC), which include equipment, construction, maintenance, and labor (Total investment cost) (eq 1).

$$
\mathrm{TIC}=\mathrm{TPDC}+\mathrm{TAC}+\mathrm{CFD}
$$

According to Table 1. The main items that influence the total direct cost of the plant (TPDC) are equipment purchase, construction, and adaptation with percentages of up to 41,11 , and $10 \%$, respectively, of the total TPDC. In contrast, the items related to the construction of the infrastructure is the element that has the most significant impact on the indirect costs of silver (TAC) (Table 2).

Table 1. Total direct plant cost (TPDC) (infrastructure costs). 


\begin{tabular}{cc}
\hline Items & (USD \$) \\
\hline 1. Equipment Purchase Cost & $7,755,000.00$ \\
2. Installation & $2,004,000.00$ \\
3. Process Piping & $1,680,000.00$ \\
4. Instrumentation & $1,921,000.00$ \\
5. Insulation & $144,000.00$ \\
6. Electrical & $480,000.00$ \\
7. Buildings & $2,161,000.00$ \\
8. Yard Improvement & $720,000.00$ \\
9. Auxiliary Facilities & $1,921,000.00$ \\
Total & $18,786,000.00$ \\
\hline
\end{tabular}

Table 2. Total Plant Indirect Cost (TAC)

\section{Items}

\begin{tabular}{cc}
\hline 10. Engineering & $3,958,000.00$ \\
11. Construction & $5,541,000.00$ \\
Total & $9,499,000.00$ \\
\hline
\end{tabular}

Table 3 shows that the costs associated with the security of the project cover up to $10 \%$ of the total needed for the implementation of the system (CFD). Finally, Tables 4 and 5 show the operational costs of the equipment and raw materials of the system in question. The culture medium is a critical parameter within the production process, occupying up to $35 \%$ of raw materials.

Table 3. Contractor's Fee \& Contingency (CFC)
(\$)

$1,267,000.00$

$2,533,000.00$

$3,800,000.00$

Table 4. Equipment's Purchase (Cost)

\begin{tabular}{cccc}
\hline Operator & Labor $(\mathbf{h} / \mathbf{y r})$ & Labor $(\mathbf{h} / \mathbf{h})$ & Labor (h/kg MP) \\
\hline V-101 : P-I & 11314.29 & 1.43 & N/A \\
ST-IOI : p-2 & $5,657.14$ & 0.71 & N/A \\
50 L : R-3. & $11,314.29$ & 1.43 & N/A \\
5L:R-2 & $11,3.1 .229$ & 1.43 & N/A \\
500 : R-4 & $11,314.29$ & 1.43 & N/A
\end{tabular}




$\begin{array}{cccc}\text { O,5L:R-1 } & 11,3.1 .229 & 1.43 & \text { N/A } \\ \text { V-102 : P-4 } & 11,314.29 & 1.43 & \text { N/A } \\ \text { R-IOI : P-7 } & 11,3.1 .229 & 1.43 & \text { N/A } \\ \text { BM-IOI : P-6 } & 5,657.14 & 0.71 & \text { N/A } \\ \text { CF-IOI : P-9 } & 1,131.43 & 0.14 & \text { N/A } \\ \text { WSH-102 : P-10 } & 5,657.14 & 0.71 & \text { N/A } \\ \text { MF-IOI : P-8 } & 13,200.00 & 1.67 & \text { N/A } \\ \text { V-103 : P-11 } & 11,314.29 & 1.43 & \text { N/A } \\ \text { FL-IOI : P-12 } & 565.71 & 0.07 & \text { N/A } \\ \text { RBS-IOI : P-13. } & 1,346.00 & 0.17 & \text { N/A } \\ \text { Section Total } & 123,728.86 & 15.62 & \text { NIA } \\ \text { TOTAL } & 123,728.86 & 15.62 & \text { N/A }\end{array}$

Table 5. Materials Cost.

\begin{tabular}{ccccc}
\hline Bulk Material & Unit Cost (\$) & Annual Amount (kg) & Annual Cost (\$) & \% \\
\hline $\mathrm{CO}_{2}$ & 0.15 & $33,342.91$ & $5,001.44$ & 0.00 \\
DMEM & 140.00 & $4,356,000.00$ & $609,840,000.00$ & 34.75 \\
DPBS & $2 ., 704.68$ & $15,840.00$ & $42,842,131.20$ & 2.45 \\
FCS & 680.00 & $475,200.00$ & $323,136,000.00$ & 18.40 \\
MDCK & 320.00 & $39,600.00$ & $12,672,000.00$ & 0.71 \\
Penicillin /strep & 250.10 & $3,064,545.92$ & $766,136,492.50$ & 43.65 \\
Potassium alum & 0.18 & $616,713.92$ & $111,008.51$ & 0.02 \\
VIRUS & $1,458.00$ & 79.2 & $115,473.60$ & 0.02 \\
& & TOTAL & $\mathbf{9 7 6 , 0 9 5 , 1 0 7 . 2 5}$ & $\mathbf{1 0 0}$ \\
\hline
\end{tabular}

\section{Upstream}

The upper part of Figure 2 shows the upstream scheme of the vaccine production system. The cells are strongly dependent on different factors such as nutrient concentration, gas injection, agitation, and other variables; therefore, the preparation and maintenance of the culture medium and culture system to be used are of great importance. In the present process, the DMEM culture medium is sterilized by dry steam (P2/ST-101) and supplemented by Fetal Bovine Serum (S-114). The scale-up process is potentially carried out to a final working volume of 500L (R4-/500) with an MDCK cell inoculum of $10 \%$ of the volume. Each reactor has a residence time of 4 days. Infection and virus adaptation was performed in stoichiometric fermentation with an infection rate of $70 \%$ of the produced cells.

\section{Downstream}

The lower part of Figure 2 shows the downstream scheme of the vaccine production system. The process of obtaining the raw material begins with a bead mill (Bead Melling 
P-6/ BM101) which accelerates cell lysis allowing the release of the viruses inside the cells; purification begins with precipitation using isopropanol at $50{ }^{\circ} \mathrm{C}$ at a ratio of $1: 2$, which is based on the differential solubility of the genetic material of the virion and is based on the decrease of the dielectric constant of the aqueous solvent, causing a decrease in the solubility of the DNA that allows the material to be separated and subsequently subjected to centrifugation (P-9/CF-101) to eliminate cellular debris.

Inactivation plays a vital role in this phase since it is only necessary to leave the genetic material inactive and the surface proteins unchanged so that it can be recognized by the immune system without affecting it, generating specialized antibodies for the destruction of its envelope, so the virion particles are chemically inactivated with binary ethylamine (BEI) [15] and subsequently purified by salting out, these residual salts that allow the concentration of the vaccine are removed by microfiltration (P-8/MF-101) after washing to facilitate the permeation of the components and eliminate suspended solids, bacteria, proteins or some dyes that may have been immersed in the inactivated virus [16]. Finally, the entire purified volume is mixed with adjuvants, Penicillin, Streptomycin, Amphotericin B, and salts as an antibiotic, antifungal, and preservative of the compound. Each vial is packed to a volume of $1 \mathrm{ml}$, containing $20 \mu \mathrm{g}$ of inactivated influenza virus for a total yield of 3,083,569,629 units/yr.

\section{Discussion}

The cases of influenza in the region of Norte de Santander are of great importance for the epidemiological monitoring of respiratory diseases since its proximity to Venezuelan cities makes it an epidemiological focus that should be monitored. According to the Regional Institute of Health of Norte de Santander, the demand for health care services for communicable conditions ranked second in 2009-2018, with a slight upward trend at all times of the life course and in both genders. Likewise, within the subgroup of communicable conditions, respiratory infections accounted for $40 \%$ of care in all general population subgroups, also showing an increasing trend in the frequency of these conditions [17]. The Expanded Program of Immunization implemented by the public health policies in Colombia guarantees free access to influenza vaccines for infants only after completing the first year of life [18]. In the case of the adult population, the free annual access to this biologic only benefits the population over 60 years of age, evidencing a failure in the coverage of access to this biologic in the general population, even more, worrisome for the population of Norte de Santander, knowing the morbidity and mortality indicators previously mentioned. Faced with this scenario, the availability of interventions to meet this public health need, including accessibility to the influenza vaccine annually within the expanded program of immunizations, could prevent two-thirds of deaths from respiratory infections in children under five years of age, as well as reduce the demand for health care due to respiratory infections in all population groups in the Region of Norte de Santander.

Based on the modeling of the manufacturing process (Figure 2) and the information about the costs of setting up the system (Tables 1 - 5), it is possible to determine that the annual revenue is estimated at $\$ 1,079$ million with an opportunity cost of sale of an additional $10 \%$ of the production value. Also, based on the sale of $\$ 0.35$ per unit, the payback period of the investment is 11.2 months, followed by annual liabilities of \$103 million. 


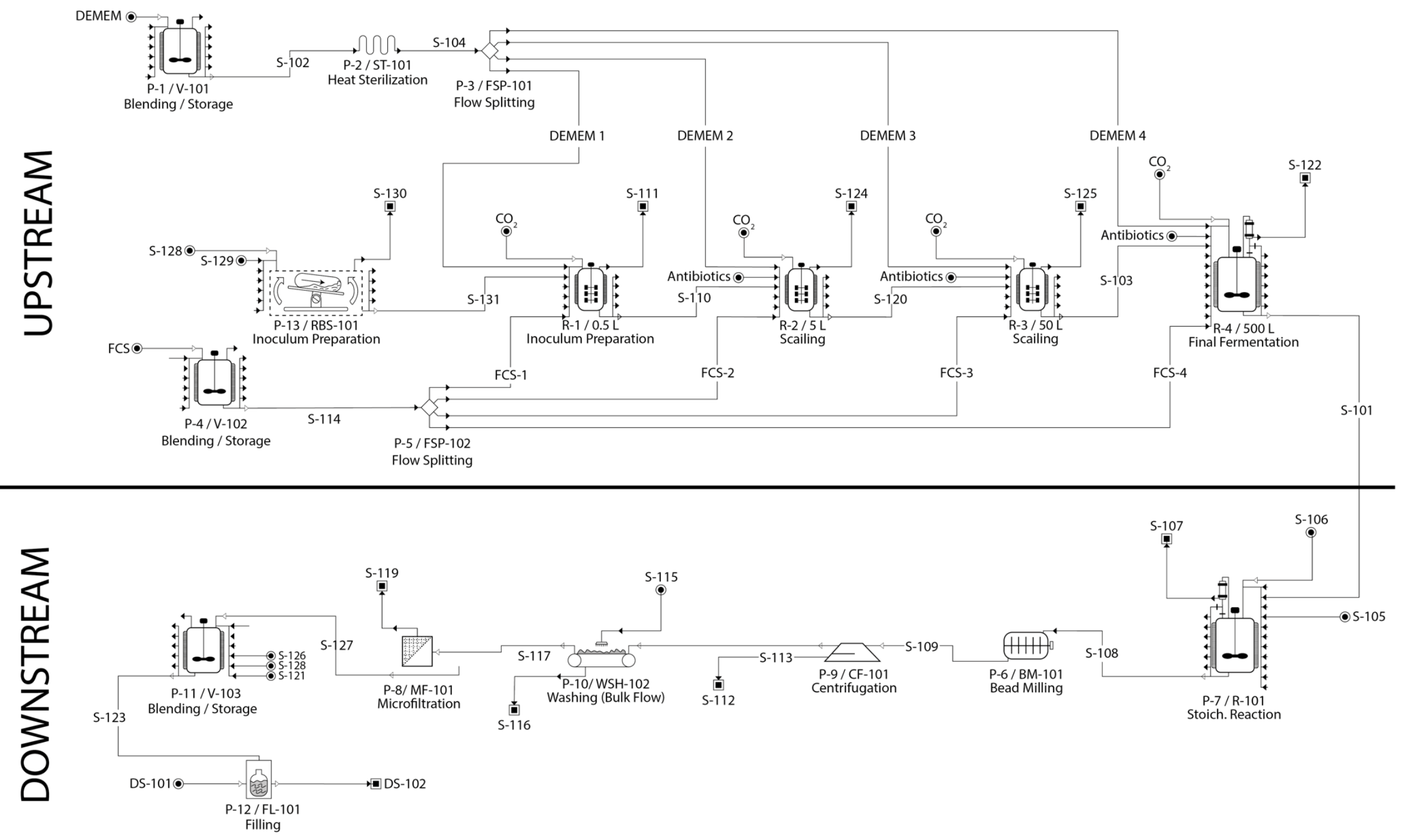

Figure 2. Flow diagram of the production, procurement, and purification process of influenza vaccine. 
The calculation of the gross cost of the product was obtained by dividing the number of doses obtained by the total cost of production, resulting in a cost of $0.31 \mathrm{USD} /$ unit, the most relevant component being the operational cost of manufacturing. In work done by Aliya Mohamad Ros et al. [19], they evaluated the production of influenza vaccines using the Vero cell line. According to their results, they identified that changes in cell line production kinetics affect the system's total cost. Likewise, and according to Farid [20] and Nestola et al. [21], the variables involved in the purification phase are the costliest (50\%), followed by the production and maintenance phase (Table 4-5). The processing, recovery, and purification of the different products associated with viral vaccines are critical processes for the stability of the process. Different techniques such as microfiltration have been considered for this stage; this technique can reduce costs by up to $70 \%$ compared to chromatography [16]. On the other hand, another possible way to reduce the size of the investment in fermentation equipment is the use of perfusion reactors; however, the difference lies in the initial investment costs since the production costs per unit are partially similar [22-24].

According to the results obtained in Tables 4 and 5, the manufacturing costs were about 30 times higher than the costs of plant establishment, mainly since the energy requirements for the physiological needs of the cell culture are high [25]. Likewise, in establishing the vaccine production system, the different costs related to vaccine supply and distribution were not considered since the literature on the optimization of vaccine production in developing countries is quite scarce. However, according to Lee et al. [26], the costs of vaccine supply chains in developing countries are as much as 5 to 28 times lower than the total cost of production [26-29]. Likewise, the model presented here does not evaluate new emerging vaccine production technologies such as Sars-CoV2 since different kinetic parameters may change the model's performance. However, it presents a lean approach to the industrial production system for vaccines of viral origin, estimating the different construction and production costs.

\section{Conclusions}

The production cost of the vaccine was estimated at 0.31 USD/unit, which is lower than the sales value of the producing pharmaceutical companies; however, this should be verified in a complete and detailed way for each operation since the midstream sector, which includes transportation, storage, and commercialization of the product, was not considered. The implementation of SuperPro Designer ${ }^{\circledR}$ as a tool allowed considering the impact of the technical and economic analysis based on experimental studies, allowing the development of improvements in different production processes in comparison with alternative unitary operations and the interaction of them with the other variables on a large scale, also exposes that the raw material and size of cell production are the key in the process.

Author Contributions: Conceptualization, J.E.C-R, J.B.G-M, and A.F.B-S; methodology, J.E.C-R, and S.L.R-R; software, J.E.C-R, and N.A.U-S.; validation, A.Z. and G.L.L-B; formal analysis, J.E.C-R and, A.Z.; investigation, J.B.G-M, and, S.L.R-R..; resources, A.F.B-S. and G.L.L-B; data curation, A.Z.; writing-original draft preparation, J.E.C-R, and, J.B.G-M.; writing-review and editing, A.F.B-S. and A.Z.; visualization, N.A.U-S; supervision, A.Z.; project administration, A.F.B-S. and N.A.U-S.; funding acquisition, A.F.B-S, N.A.U-S, and, G.L.L-B. All authors have read and agreed to the published version of the manuscript.

Funding: This paper was supported by Universidad Industrial de Santander and the Colombian Ministry of Science Technology and Innovation MINCIENCIAS with the project "strengthening of the scientific-technological capabilities of the molecular biology Laboratory-UFPS as a tool for the biology laboratory as a tool for the diagnosis of biological agents of high risk to human health" BPIN 2020000100123.

Acknowledgments: We would like to express our sincere gratitude to Universidad Francisco de Paula Santander (Colombia) and Sapienza University of Rome (Italy) for providing the equipment 
for this review and the Colombian Ministry of Science Technology and Innovation MINCIENCIAS for the support to national Ph.D. Doctorates through the Francisco José de Caldas scholarship program.

Conflicts of Interest: The authors declare no conflict of interest.

2. Instituto Nacional de Salud. Acute respiratory infection event report, Colombia, 2019. Available online: https://www.ins.gov.co/buscador-eventos/Informesdeevento/INFECCIÓN\%20RESPIRATORIA\%20AGUDA 2019.pdf $\quad$ (accessed on 11 September 2021).

3. Ministerio de Salud y Protección Social de Colombia. Ten-Year Public Health Plan 2012-2021 of Colombia. 2012. Available online: https://www3.paho.org/hq/index.php?option=com content\&view=article\&id=8777:2013-plan-decenal-salud-publica2012-2021-colombia\&Itemid=40264\&lang=es. (accessed on 11 September 2021).

4. Ministerio de Salud y Protección Social de Colombia. ABC of the Ten-Year Public Health Plan. Available online: https://www.minsalud.gov.co/sites/rid/Lists/BibliotecaDigital/RIDE/VS/ED/PSP/IMP 4feb+ABCminsalud.pdf. (accessed on 11 September 2021).

5. Athimulam, A.; Kumaresan, S.; Foo, D. C. Y.; Sarmidi, M. R.; Aziz, R. A. Modelling and Optimization of Eurycoma Longifolia Water Extract Production. Food Bioprod. Process. 2006, 84 (2), 139-149. https://doi.org/https://doi.org/10.1205/fbp.06004.

6. Sparrow, E.; Wood, J. G.; Chadwick, C.; Newall, A. T.; Torvaldsen, S.; Moen, A.; Torelli, G. Global Production Capacity of Seasonal and Pandemic Influenza Vaccines in 2019. Vaccine 2021, 39 (3), 512-520. https://doi.org/https://doi.org/10.1016/j.vaccine.2020.12.018.

7. Jiang, B.; Patel, M.; Glass, R. I. Polio Endgame: Lessons for the Global Rotavirus Vaccination Program. Vaccine 2019, 37 (23), 3040-3049. https://doi.org/https://doi.org/10.1016/j.vaccine.2019.04.023.

8. Canizales, L.; Rojas, F.; Pizarro, C. A.; Caicedo-Ortega, N. H.; Villegas-Torres, M. F. SuperPro Designer®, User-Oriented Software Used for Analyzing the Techno-Economic Feasibility of Electrical Energy Generation from Sugarcane Vinasse in Colombia. Processes. 2020. 8(9), 1180 https://doi.org/10.3390/pr8091180.

9. Ernst, S.; Garro, O. A.; Winkler, S.; Venkataraman, G.; Langer, R.; Cooney, C. L.; Sasisekharan, R. Process Simulation for Recombinant Protein Production: Cost Estimation and Sensitivity Analysis for Heparinase I Expressed in Escherichia Coli. Biotechnol. Bioeng. 1997, 53 (6), 575-582. https://doi.org/https://doi.org/10.1002/(SICI)1097-0290(19970320)53:6<575::AID-BIT5>3.0.CO;2I.

10. Genzel, Y. Designing Cell Lines for Viral Vaccine Production: Where Do We Stand? Biotechnol. J. 2015, 10 (5), 728-740. https://doi.org/https://doi.org/10.1002/biot.201400388.

11. Fontana, D.; Marsili, F.; Garay, E.; Battagliotti, J.; Etcheverrigaray, M.; Kratje, R.; Prieto, C. A Simplified Roller Bottle Platform for the Production of a New Generation VLPs Rabies Vaccine for Veterinary Applications. Comp. Immunol. Microbiol. Infect. Dis. 2019, 65, 70-75. https://doi.org/https://doi.org/10.1016/j.cimid.2019.04.009.

12. Sheridan, P. L.; Bodner, M.; Lynn, A.; Phuong, T. K.; DePolo, N. J.; de la Vega Jr., D. J.; O’Dea, J.; Nguyen, K.; McCormack, J. E.; Driver, D. A.; Townsend, K.; Ibañez, C. E.; Sajjadi, N. C.; Greengard, J. S.; Moore, M. D.; Respess, J.; Chang, S. M. W.; Dubensky Jr., T. W.; Jolly, D. J.; Sauter, S. L. Generation of Retroviral Packaging and Producer Cell Lines for Large-Scale Vector Production and Clinical Application: Improved Safety and High Titer. Mol. Ther. 2000, 2 (3), 262-275. https://doi.org/10.1006/mthe.2000.0123.

13. Limonta, M.; Krajnc, N. L.; Vidic, U.; Zumalacárregui, L. Simulation for the Recovery of Plasmid for a DNA Vaccine. Biochem. Eng. J. 2013, 80, 14-18. https://doi.org/https://doi.org/10.1016/j.bej.2013.09.006.

14. Petrides, D.; Carmichael, D.; Siletti, C.; Koulouris, A. Biopharmaceutical Process Optimization with Simulation and Scheduling Tools. Bioengineering. 2014. 1(4), 154-187. https://doi.org/10.3390/bioengineering1040154.

15. Valero, Y.; Olveira, J. G.; López-Vázquez, C.; Dopazo, C. P.; Bandín, I. BEI Inactivated Vaccine Induces Innate and Adaptive Responses and Elicits Partial Protection upon Reassortant Betanodavirus Infection in Senegalese Sole. Vaccines. 2021. 9(5), 458. https://doi.org/10.3390/vaccines9050458.

16. Moyle, P. M. Progress in Vaccine Development. Curr. Protoc. Microbiol. 2015, 36 (1), 18.1.1-18.1.26. https://doi.org/https://doi.org/10.1002/9780471729259.mc1801s36.

17. Instituto Departamental de Salud. Health Situation Analysis with the Social Determinants Model Norte de Santander Department 2019. 2019. Available online: $\underline{\text { https://ids.gov.co/web/2020/TRANSPAREN- }}$ CIA/ASIS DPTAL NTE\%20SDER 2019 ABRIL 2020.pdf (accessed on 11 September 2021).

18. Ministerio de Salud y Protección Social de Colombia. Guidelines for the management and administration of the expanded program of immunization - PAI - 2020. 2020. Available online: https://www.minsalud.gov.co/sites/rid/Lists/BibliotecaDigital/RIDE/VS/PP/ET/lineamientos-nacionales-pai2020.pdf (accessed on 11 September 2021). 9 . 1 2 . 67 68 69 70 71 72 73 74 
19. Aliya Mohamad Ros, F. N.; Abd Rahman, N.; Mohd Ali, J.; Anuar, N.; Sheikh Abdullah, S. R. B.; Fazlim Bin Jusoh Yusoff, A. Comparative Study between Avian Cell and Mammalian Cell in Production of Influenza Vaccine Shariah Compliance. IOP Conf. Ser. Mater. Sci. Eng. 2020, 778, 12029. https://doi.org/10.1088/1757-899x/778/1/012029.

20. Farid, S. S. Process Economics of Industrial Monoclonal Antibody Manufacture. J. Chromatogr. B 2007, 848 (1), $8-18$. https://doi.org/https://doi.org/10.1016/j.jchromb.2006.07.037.

21. Nestola, P.; Peixoto, C.; Silva, R. R. J. S.; Alves, P. M.; Mota, J. P. B.; Carrondo, M. J. T. Improved Virus Purification Processes for Vaccines and Gene Therapy. Biotechnol. Bioeng. 2015, 112 (5), 843-857. https://doi.org/https://doi.org/10.1002/bit.25545.

22. Yang, W. C.; Lu, J.; Kwiatkowski, C.; Yuan, H.; Kshirsagar, R.; Ryll, T.; Huang, Y.-M. Perfusion Seed Cultures Improve Biopharmaceutical Fed-Batch Production Capacity and Product Quality. Biotechnol. Prog. 2014, 30 (3), $616-625$. https://doi.org/https://doi.org/10.1002/btpr.1884.A

23. Tapia, F.; Vázquez-Ramírez, D.; Genzel, Y.; Reichl, U. Bioreactors for High Cell Density and Continuous Multi-Stage Cultivations: Options for Process Intensification in Cell Culture-Based Viral Vaccine Production. Appl. Microbiol. Biotechnol. 2016, 100 (5), 2121-2132. https://doi.org/10.1007/s00253-015-7267-9.

24. Xu, J.; Xu, X.; Huang, C.; Angelo, J.; Oliveira, C. L.; Xu, M.; Xu, X.; Temel, D.; Ding, J.; Ghose, S.; Borys, M. C.; Li, Z. J. Biomanufacturing Evolution from Conventional to Intensified Processes for Productivity Improvement: A Case Study. MAbs 2020, 12 (1), 1770669. https://doi.org/10.1080/19420862.2020.1770669.

25. Pérez Rubio, A.; Eiros, J. M. Cell Culture-Derived Flu Vaccine: Present and Future. Hum. Vaccin. Immunother. 2018, 14 (8), 18741882. https://doi.org/10.1080/21645515.2018.1460297.

26. Lee, B. Y.; Connor, D. L.; Wateska, A. R.; Norman, B. A.; Rajgopal, J.; Cakouros, B. E.; Chen, S.-I.; Claypool, E. G.; Haidari, L. A.; Karir, V.; Leonard, J.; Mueller, L. E.; Paul, P.; Schmitz, M. M.; Welling, J. S.; Weng, Y.-T.; Brown, S. T. Landscaping the Structures of GAVI Country Vaccine Supply Chains and Testing the Effects of Radical Redesign. Vaccine 2015, 33 (36), $4451-4458$. https://doi.org/https://doi.org/10.1016/j.vaccine.2015.07.033.

27. Chen, S.-I.; Norman, B. A.; Rajgopal, J.; Assi, T. M.; Lee, B. Y.; Brown, S. T. A Planning Model for the WHO-EPI Vaccine Distribution Network in Developing Countries. IIE Trans. 2014, 46 (8), 853-865. https://doi.org/10.1080/0740817X.2013.813094.

28. Haidari, L. A.; Connor, D. L.; Wateska, A. R.; Brown, S. T.; Mueller, L. E.; Norman, B. A.; Schmitz, M. M.; Paul, P.; Rajgopal, J.; Welling, J. S.; Leonard, J.; Chen, S.-I.; Lee, B. Y. Augmenting Transport versus Increasing Cold Storage to Improve Vaccine Supply Chains. PLoS One 2013, 8 (5), e64303. https://doi.org/10.1371/journal.pone.0064303.

29. Lemmens, S.; Decouttere, C.; Vandaele, N.; Bernuzzi, M. A Review of Integrated Supply Chain Network Design Models: Key Issues for Vaccine Supply Chains. Chem. Eng. Res. Des. 2016, 109, 366-384. https://doi.org/https://doi.org/10.1016/j.cherd.2016.02.015. 